引用格式: 丁振民, 姚顺波. 小尺度区域生态补偿标准的理论模型设计及测度 [J]. 资源科学, 2019, 41(12): 2182-2192. [Ding Z M, Yao S B. Model and measurement of payment for ecosystem services at small scale[J]. Resources Science, 2019, 41(12): 21822192.] DOI: $10.18402 /$ resci.2019.12.03

\title{
小尺度区域生态补偿标准的理论模型 设计及测度
}

\author{
丁振民 $^{1,2}$, 姚顺波 ${ }^{1,2}$
}

(1. 西北农林科技大学资源经济与环境管理研究中心,杨凌 712100 ;

2. 西北农林科技大学经济管理学院, 杨凌 712100)

\begin{abstract}
摘 要: 本文以环境正义理论为基础通过构建土地利用转移几率比与生态系统服务价值之间的函数关系, 以 解决小尺度下社会经济统计数据缺失无法进行生态补偿测算的问题。研究结果表明: (1)本文设计的区域生态补偿 理论模型可以有效地解决小尺度下社会经济数据缺失导致区域生态补偿无法进行测算的问题; 并且该模型划分的 湖北省生态补偿区与生态受偿区分别与重点开发区、重点生态功能区的空间格局保持一致,验证了小尺度下区域 生态补偿理论模型的可靠性。(2)湖北省整体生态环境水平存在恶化的趋势。2000-2015年湖北省生态补偿乡镇 数量和总金额整体呈现上升的趋势, 而生态受偿乡镇数量和总金额整体呈现下降的趋势。2015 年湖北省乡镇生态 补偿总额为 17.25 亿元, 生态受偿总金额为 29.54 亿元, 相比 2000 年分别增长了 $19.96 \% 、-6.99 \%$; 另外, 生态补偿与 生态受偿空间格局基本保持不变, 但局部地区略有变动。本文设计的生态补偿理论模型可以为小尺度下空间生态 失衡提供解决思路与方案。
\end{abstract}

关键词: 生态补偿;环境正义;生态系统服务价值;理论模型; 小尺度;湖北省

DOI :10.18402/resci.2019.12.03

\section{1 引言}

随着中国社会经济的高速发展以及城镇化进 程的不断推进, 区域间生态环境与经济发展失衡和 利益错配的问题日益严重 ${ }^{[1]}$ 。区域之间发展的不平 衡、不协调影响到社会福利在不同群体间的公平分

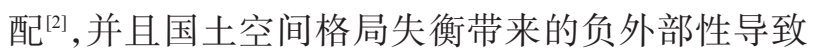
人与自然之间的矛盾愈演愈烈 ${ }^{[3,4]}$ 。探索区域间以 地方政府为主导的横向生态补偿机制是生态文明 建设的重要命题与区域协调发展的制度供给 ${ }^{[5,6]}$ 。

生态补偿标准的确定是区域生态补偿制度设 计的核心问题。区域生态补偿标准一般包含生态 补偿理论选择、计价基础确定和补偿标准设计 3 个
方面。从理论基础来看, 外部性理论、生态资本理 论以及环境正义理论构成生态补偿的哲学基础与 理论基石。外部性理论以人为中心, 注重有效地运 用市场或者政府干预机制解决生态环境问题 ${ }^{[7,8]}$; 但 外部性理论依赖初始产权的分配以及强调交易效 率, 而忽略了生态资源分配与使用的公平性。生态 资本理论认为生态系统服务也具有稀缺性, 为人类 生产生活提供基本的生态空间与支撑系统,应当建 立有效的生态资本有偿使用制度 ${ }^{[9]}$; 然而由于受益 群体模糊、受益大小计量困难等问题的存在导致生 态产品或者服务难以形成有效的交易市场。环境 正义理论强调每个主体在资源环境使用和保护上

收稿日期:2019-07-03 修订日期:2019-10-04

基金项目:林业公益性行业科研专项经费项目(201504424);国家自然科学基金项目(71773091); 教育部人文社会科学重点研究基地基金项目 (14JJD790031)。

作者简介: 丁振民,男,安徽淮北人,博士研究生,研究方向为林业经济管理、资源经济与环境管理。E-mail: huanglishanren@sina.com 通讯作者: 姚顺波, 男, 湖南益阳人, 教授, 博士生导师, 研究方向林业经济政策与理论、资源经济与环境管理。E-mail: yaoshunbo@163.com 
具有相同权利, 同时也需要履行相应的义务 ${ }^{[10,11]}$; 其 可以保证初始的资源环境分配和后期资源环境使 用的公平性,并不完全依赖于有效的交易市场。从 计价基础来看,多数研究以机会成本法和生态系统 服务价值法作为生态补偿标准的计价基础。机会 成本法多适用于微观层面的生态补偿, 但是由于个 体之间存在信息不对称的问题, 导致生态补偿标准 的制定往往难以体现公平 ${ }^{[12]}$; 而生态系统服务价值 法由于在区域层面核算较为简单方便被广泛地应 用于区域之间的横向生态补偿标准的设计 ${ }^{[13-16]}$ 。从 生态补偿标准设计来看, 区域生态补偿以生态系统 服务价值减去治理污染投人的实际成本的差额 法 ${ }^{[13,14]}$ 和生态系统服务价值乘以生态盈余系数的分 摊法为主导 ${ }^{[15,16]}$ 。在区域生态补偿中, 无论是差额 法还是分推法均以其社会经济数据构造统计参数, 但是在小尺度 (乡镇、村)层面难以获取计算相关统 计参数的基础数据, 所以现有的区域生态补偿模型 主要应用于省域、市域以及县域层面, 无法解决更 小尺度下空间生态失衡的问题。如何设计一种可 以有效规避统计参数的生态补偿标准是解决小尺 度下空间生态失衡的关键。

为了有效地解决小尺度下社会经济统计数据 缺失的问题, 本文以土地利用栅格数据为基础, 运 用环境正义理论设计一种可以解决小尺度下区域 生态失衡的生态补偿理论模型。首先, 构建土地利 用转移与自然、社会经济因素之间的函数关系; 然 后, 在环境正义理论的基础上运用经济数学的方法 推导区域生态补偿标准的理论模型; 最后, 以湖北 省乡镇单元为例对区域生态补偿金额的时空特征 进行分析, 以验证本文设计的小尺度区域生态补偿 标准的可靠性, 以期为乡镇层面的生态环境治理与 区域协调发展提供一个合理的参考。

\section{2 理论基础与模型设计}

土地利用/土地覆被变化 (Land Use/land Cover Change, LUCC) 是人类与自然耦合系统的核心环 节, 也是自然因素和社会经济因素共同作用的结 果 ${ }^{[17]}$ 。那么用经济数学的方式可以把社会经济因素 与自然因素对 LUCC 的作用方式表达为:

$$
\boldsymbol{P}=\alpha(\text { economic }, \text { nature })+\varepsilon
$$

式中: $\boldsymbol{P}=\left[\begin{array}{cccc} & p_{12} & \cdots & p_{1 j} \\ p_{21} & & \cdots & p_{2 j} \\ \cdots & \cdots & & \cdots \\ p_{i 1} & p_{i 2} & \cdots & \end{array}\right]$ 为土地利用转移概率 矩阵; $p_{i j}$ 表示第 $i$ 类土地向第 $j$ 类土地转移的概率， $i \neq j ;$ economic 表示社会经济因素组成的向量; nature 表示自然因素组成的向量; $\varepsilon$ 为残差; $\alpha(\cdot)$ 为 函数符号。

然而土地利用转移概率只能反映土地相互之 间转移的概率, 难以衡量土地利用转移相对风险的 变化。几率比(Odds Rate) 是目前衡量相对风险使 用频率最多、最有影响力的替代指标之一 ${ }^{[18]}$, 表示一 个群体暴露在一定风险下某事件发生的概率与未 暴露在该风险下某事件发生概率的比值, 又称相对 风险 ${ }^{[19]}$ 。因此, 本文利用土地利用转移几率比矩阵 衡量地类之间转移的可能性, 即 :

$$
\boldsymbol{O D D S}=\left[\begin{array}{cccc} 
& \frac{p_{12}}{1-p_{12}} & \cdots & \frac{p_{1 j}}{1-p_{1 j}} \\
\frac{p_{21}}{1-p_{21}} & & \cdots & \frac{p_{2 j}}{1-p_{2 j}} \\
\cdots & \cdots & & \cdots \\
\frac{p_{i 1}}{1-p_{i 1}} & \frac{p_{i 2}}{1-p_{i 2}} & \cdots &
\end{array}\right]
$$

那么, 土地利用转移的几率比矩阵同样受到自 然因素和社会经济因素的约束, 即土地利用转移几 率比矩阵的决定方程为:

$$
\begin{aligned}
\text { ODDS } & =g[\alpha(\text { economic }, \text { nature })]+\mu \\
& =\frac{\alpha(\text { economic }, \text { nature })}{1-\alpha(\text { economic }, \text { nature })}+\mu
\end{aligned}
$$

式中: $\boldsymbol{O D D S}$ 为土地利用转移几率比矩阵; $\mu$ 为 残差; $g(\cdot)$ 为函数符号。

作为陆地表层系统中最重要的景观, 土地利用/ 覆被变化主要通过作用生态系统结构以及生态系 统类型的空间分布进而改变生态系统服务的供给 能力和功能状态 ${ }^{[2,21]}$; 另外, 生态系统服务不仅受土 地利用变化的影响, 还与前期初始生态禀赋有着密 不可分的关系, 遗漏初始生态禀赋可能造成估计结 果存在偏差 ${ }^{[22]}$ 。生态系统服务价值(Ecosystem Service Value, ESV) 作为综合反映生态系统服务功能 替代指标, 可以很好地衡量生态系统服务的质量。 那么,生态系统服务价值对土地利用变化与初始生 态系统禀赋的响应函数可以表示为: 


$$
E S V_{t}=f(\boldsymbol{O D D S})+\delta E S V_{t-1}+\gamma
$$

式中: $E S V$ 表示生态系统服务价值; $t$ 表示时间; $\delta$ 表 示估计系数; $\gamma$ 表示残差; $f(\cdot)$ 为函数符号。

在式 (4) 中引人土地利用转移几率比矩阵的决 定方程,可得:

$$
\begin{aligned}
E S V_{t} & =f(\text { ODD })+\delta E S V_{t-1}+\gamma \Leftrightarrow E S V_{t} \\
& =f\left(\frac{\alpha(\text { economic }, \text { nature })}{1-\alpha(\text { economic }, \text { nature })}\right)+\delta E S V_{t-1}+\gamma
\end{aligned}
$$

所以, 可以利用生态系统服务价值对土地利用 转移几率比矩阵的响应函数近似地替代生态系统 服务价值与社会经济因素、自然因素之间的函数关 系, 以此达到消除生态补偿中含有统计参数的目的。

生态经济学是以生态可持续性、分配正义为优 先原则, 试图使经济制度与生态系统服务的物理特 性相适应 ${ }^{[23]}$ 。环境正义理论认为个人、群体、以及区 (国)际之间均拥有改造自然的平等权利, 同时也要 履行保护自然的平等义务 ${ }^{[10,11]}$ 。那么在区域层面, 某 些区域可能承担了保护环境的成本, 却没有享受到 保护生态环境的收益, 而在其他区域可能相反。这 就造成区域生态环境占用权利与保护义务的不对 等, 高生态环境占用行为区域必须向低生态环境占 用行为区域进行付费, 或者低生态环境保护行为区 域向高生态环境保护行为区域进行付费, 以保证区 域之间的环境正义。那么如何设定生态环境正义 分配的标准呢? 假设在区域 $\mathrm{A}$ 中发生了一个活动 对生态环境造成的影响为 $k$, 那么在 $\mathrm{B}$ 区域中该活 动对生态环境造成的影响也为 $k$, 这时我们可以说 区域 $\mathrm{A}$ 与 $\mathrm{B}$ 承担着相同的环境责任或者享受着相同 的环境权利。因此在土地利用转移几率比矩阵中, 可以理解为在不同区域内各要素变动对生态环境 影响的边际效应是相同的, 即在理论上土地利用变 化转移几率比对生态系统服务价值的边际贡献为 $\frac{\partial E S V}{\partial \boldsymbol{O D D S}}$ 。但是现实中, 由于区域环境条件以及人 类活动改造自然的方式存在差异, 导致实际上各要 素对生态环境的边际效应在区域上存在明显的差 异; 这就使得在某一区域内实际的土地利用转移几 率比对生态系统服务价值的边际贡献 $\frac{\partial E S V_{m}}{\partial O D D S}$ 与理 论上的边际贡献 $\frac{\partial E S V}{\partial O D D S}$ 存在符号一致但大小不相
等的情况。如果理论上的边际贡献 $\frac{\partial E S V}{\partial \boldsymbol{O D D S}}$ 大于实 际的边际贡献 $\frac{\partial E S V_{m}}{\partial \boldsymbol{O D D S}}$, 即土地利用几率比变动引 起的生态系统服务价值理论变化量大于实际变化 量, 即 $\frac{\partial E S V}{\partial \boldsymbol{O D D} \boldsymbol{S}}-\frac{\partial E S V_{m}}{\partial \boldsymbol{O D D D S}}>0$, 那么区域 $m$ 则为生态 补偿区 (Payment Zone, PZ); 反之, 则区域 $m$ 为生态 受偿区 (Acception for Payment Zone, APZ)。那么 区域 $m$ 接受的生态补偿金额为:

$$
\begin{aligned}
\text { payment }_{m} & =\left(\frac{\partial E S V}{\partial \boldsymbol{O D D S}}-\frac{\partial E S V_{m}}{\partial \boldsymbol{O D D} \boldsymbol{S}}\right) \times \boldsymbol{O D D S} \\
& =\left(E \hat{S} V_{m}-\delta E S V_{t-1}\right)-\left(E S V_{m}-\delta E S V_{t-1}\right) \\
& =\left(E \hat{S} V_{m}-E S V_{m}\right)
\end{aligned}
$$

式中: $E \hat{S} V_{m}$ 是区域 $m$ 生态系统服务价值的预测 值;则生态补偿区的集合可以表示为:

$$
P Z=\left\{m \mid E S V_{m}<E \hat{S} V_{m}\right\}
$$

另外, 根据回归理论可知, E $\left(\right.$ payment $\left._{m}\right)=$ $\left(E \hat{S} V_{m}-E S V_{m}\right)=E(\gamma)=0$, 则该模型可以保证总量上 生态补偿与生态受偿金额相等。

为了更加直观地反映环境正义理论下区域生 态补偿标准理论模型的推导过程, 假设存在 A、B、C 三个区域,并且区域生态系统服务价值只受到一个 土地利用转移几率比因子的影响(图 1)。 $\mathrm{A}^{\prime} 、 \mathrm{~B}^{\prime}$ 、 $\mathrm{C}^{\prime}$ 表示生态系统服务价值在受到一个土地利用转 移几率比因子影响时应该达到的理论值。那么, 可 以看出区域 $\mathrm{A}$ 生态系统服务价值的实际值与预测 值相等, 表示 $\mathrm{A}$ 点处于生态补偿的临界区, 其需要

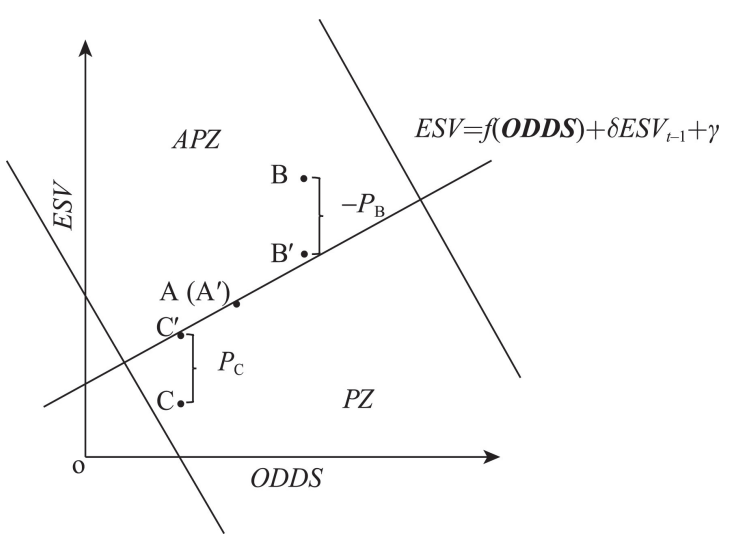

图 1 生态补偿标准的理论模型设计

Figure 1 Theoretical model of payment for ecosystem services 
支付 (接受) 的生态补偿金额为 0 ; 区域 $\mathrm{B}$ 的生态系 统服务价值的实际值大于预测值, 表明区域 $\mathrm{B}$ 为生 态受偿区, 受偿金额为 $P_{\mathrm{B}}$; 而区域 $\mathrm{C}$ 的生态系统服 务价值的实际值小于理论值, 表明区域 C 为生态补 偿区, 补偿金额为 $P_{\mathrm{C}}$ 。

\section{3 研究区概况、研究方法与数据}

\section{1 研究区概况}

湖北省 $\left(108^{\circ} 21^{\prime} \mathrm{E}-116^{\circ} 07^{\prime} \mathrm{E}, 29^{\circ} 01^{\prime} \mathrm{N}-33^{\circ}\right.$ $06^{\prime} \mathrm{N}$ ) 位于长江中游地区, 是承东启西、连南接北的 重要交通枢纽, 同时也是长江经济带等国家重要战 略的组成部分。地形条件复杂多样, 以丘陵山地为 主; 三面环山、中间为江汉平原。气候以亚热带季 风气候为主, 年平均气温约为 $15 \sim 17^{\circ} \mathrm{C}$, 年均降水量 在 800 1600 mm 之间,气温和降水地域分布均呈由 东南向西北递减趋势。境内水系发达,长江横贯东 西; 湖泊众多,素有“千湖之省”的美誉。截至 2018 年末,湖北省现有乡镇(街道) 1073 个, GDP 达到 39366.55 亿元, 常住人口 5917 万, 其中, 城镇人口 3567.95 万, 城镇化率达到 $68.65 \%$ 。

2012 年, 为了实现人口、经济和资源环境相协 调的国土空间开发格局,湖北省政府办公厅确定以 城市圈为核心的湖北省国家层面重点开发区域,并 且划定了湖北省以东、北、西三面山区为重点生态 功能区 ${ }^{[24]}$ 。这对于检验本文设计的生态补偿理论模 型的合理性具有重要的作用。2018年, 为了加快推 进生态文明建设、进一步贯彻落实十九大报告精 神, 湖北省政府颁布了《关于建立健全生态保护补
偿机制的实施意见》(鄂政办发 [2018]1 号) ${ }^{[25]}$ 。意 见要求充分发挥政府对生态环境保护的主导作用, 建立完善生态保护和补偿的分级责任、构建可持续 的生态补偿长效机制, 逐步确立与社会经济发展状 况相适应的生态保护补偿制度体系,促进形成绿色 生产方式和生活方式。

\section{2 研究方法}

3.2.1 生态系统服务价值计算

生态系统服务是指能够有效地满足人类生存 与提高人类生活水平的生态产品和服务 ${ }^{[26]}$ 。自 1999年 Constanza 等 ${ }^{[27]}$ 比较全面地评估了全球生态 系统服务价值以来,其核算理论与方法在全球范围 内不断发展与完善。本文以谢高地等 ${ }^{[28]}$ 修订的比较 符合中国实际情况的“中国生态系统单位面积生态 服务价值当量表”为核算基础,借鉴熊鹰等 ${ }^{[29]}$ 对不同 地类的各种生态系统服务价值当量因子的确定, 其 中城乡建设用地的当量因子参考 Constanza 等 ${ }^{[27]}$ 的 研究成果。利用湖北省 $1 \mathrm{hm}^{2}$ 耕地年平均粮食产量 经济价值的 $1 / 7$ 和区域修正系数(湖北省为 1.27 ) 对 各地类每种服务的当量因子的经济价值进行修正， 修正后 1990-2015 年湖北省一个生态系统服务当 量因子的平均经济价值为 2016.60 元 $/\left(\mathrm{hm}^{2} \cdot \mathrm{a}\right.$ ) (统一 折算为 2015 年的实际价格),最终得到湖北省各地 类的生态价值系数表 $($ 表 1$)$ 。

由于区域生态系统服务价值受到区域面积大 小的影响, 导致其在不同区域上缺乏可比性。因 此,本文利用区域生态系统服务总价值除以区域面

表 1 湖北省各地类生态价值系数

Table 1 Ecological value coefficient of terrestrial ecosystems in Hubei Province

$\left(\right.$ 元 $\left./\left(\mathrm{hm}^{2} \cdot \mathrm{a}\right)\right)$

\begin{tabular}{lrrrrrr}
\hline \multicolumn{1}{c}{ 生态系统服务 } & 耕地 & 林地 & 草地 & 水域 & 城乡建设用地 & 未利用地 \\
\hline 气体交换 & 1451.95 & 8711.71 & 3024.90 & 1028.46 & 0.00 & 120.99 \\
气候调节 & 1956.10 & 8207.56 & 3145.89 & 4154.19 & 0.00 & 262.16 \\
水源涵养 & 1552.78 & 8247.90 & 3065.23 & 37851.57 & 0.00 & 141.16 \\
土壤形成与保护 & 2964.40 & 8106.73 & 4517.19 & 826.80 & 0.00 & 342.82 \\
废物处理 & 2803.08 & 3468.55 & 2661.91 & 29946.50 & 0.00 & 524.31 \\
生物多样性保护 & 2056.93 & 9094.86 & 3771.04 & 6916.93 & 0.00 & 806.64 \\
食物生产 & 2016.60 & 665.48 & 867.14 & 1068.80 & 0.00 & 40.33 \\
原材料 & 786.48 & 6009.46 & 725.97 & 705.81 & 0.00 & 80.67 \\
娱乐休闲 & 342.82 & 4194.52 & 1754.44 & 54.32 & 0.00 & 483.99 \\
生态价值系数 $\left(v c_{k}\right)$ & 15931.13 & 56706.78 & 23533.71 & 82553.41 & & 0.00 \\
\hline
\end{tabular}


积得到具有可比性的单位面积生态系统服务价值 作为因变量以纳人回归模型 ${ }^{\circledR}$, 模型如下:

$$
m e s v_{m t}=\frac{\sum v c_{k} \times s_{m t, k}}{\sum s_{m t, k}}
$$

式中: $m e s v_{m t}$ 为乡镇 $m$ 第 $t$ 期单位面积的生态系统服 务价值; $v c_{k}$ 为第 $k$ 类土地利用类型的生态价值系数; $S_{m t, k}$ 为乡镇 $m$ 第 $t$ 期第 $k$ 类土地利用类型的面积。

\subsection{2 土地利用转移几率比}

本文利用土地利用转移几率比衡量土地利用 类型之间相互转移的可能性。首先在 ArcGIS 中利 用面积制表功能计算 2 期土地利用转移矩阵, 然后 计算土地利用转移几率比:

$$
o d d S_{m t, i j}=\frac{p_{m t, i j}}{1-p_{m t, i j}} \quad(i \neq j)
$$

式中: $o d d s_{m, t i j}$ 表示乡镇 $m$ 第 $t$ 期土地利用类型 $i$ 向土 地利用类型 $j$ 转移的几率比; $p_{m, i j}$ 表示乡镇 $m$ 第 $t$ 期 土地利用类型 $i$ 向土地利用类型 $j$ 转移的概率。

\subsection{3 生态补偿标准测度}

首先, 由于最小二乘法 (OLS) 容易因遗漏无法 观测变量带来的内生性问题导致计算的生态系统 服务价值的预测值存在很大的偏误，而固定效应面 板模型在一定程度上可以解决 OLS 因遗漏变量估 计有偏的问题。因此,本文运用固定效应面板模型 估计各乡镇生态系统服务价值的预测值, 模型 如下:

$$
m e s v_{m t}=\sum_{j=1}^{6} \sum_{i=1}^{6} b_{i j} O d d s_{m, i j}+p \text { mes } v_{m, t-1}+\pi_{m}+\omega_{m t}
$$

式中: $b_{i j} p$ 为模型估计系数; $m e s v_{m, t-1}$ 表示乡镇 $m$ 第 $t-1$ 期的单位面积生态系统服务价值; $\pi_{m}$ 表示个体 效应; $\omega_{m t}$ 为残差项。

其次,计算单位面积生态系统服务价值的预测 值与实际值的差值并且乘以乡镇面积作为乡镇生 态补偿金额：

$$
\text { payment }_{m t}=\left(\hat{m e s v}_{m t}-m e s v_{m t}\right) \times s_{m t}
$$

式中: payment $_{m t}$ 表示乡镇 $m$ 第 $t$ 期生态补偿金额; $s_{m t}$ 表示第 $t$ 期乡镇 $m$ 的行政区域面积。

\section{3 数据来源与处理}

$1990 、 2000 、 2005 、 2010$ 与 2015 年湖北省 $30 \mathrm{~m}$
的土地利用分类数据来自于中国科学院资源环境 科学数据中心 (http://www.resdc.cn); 数据的生产制 作是以各期 Landsat $\mathrm{TM} / \mathrm{ETM} / 8$ 遥感影像为主要数 据源通过人工目视解译生成; 并且一级类型综合评 价精度达到 $94.3 \%$ 以上 ${ }^{[30]}$ 。为了研究需要, 根据《中 国科学院土地利用/覆盖分类体系标准 $\rangle^{[30]}$, 利用 ArcGIS 将湖北省的土地利用类型重新划分为耕地、 林地、草地、水域、城乡建设用地以及未利用地等 6 类。另外,湖北省粮食价格、单位面积粮食产量等 农产品相关数据来源于各年份的《全国农产品成本 收益汇编 $\rangle^{[31]}$; 居民消费价格指数 $(\mathrm{CPI})$ 等数据来源 于国家统计局网站 (http://www.stats.gov.n/)。在相 关数据和模型的基础之上, 可以计算出生态系统服 务价值、生态系统服务价值预测值以及各土地利用 转移几率比,其变量的描述性统计见表 2 。

湖北省 1990-2015 年各乡镇的平均生态系统 服务价值为 36209.84 元 $/ \mathrm{hm}^{2}$, 并且与其预测值保持 一致。1990-2015 年间湖北省耕地转出因子比较 活跃, 其中最为活跃的是耕地 $\rightarrow$ 城乡建设用地、耕 地 $\rightarrow$ 水域土地利用转移几率比因子, 其平均值分别 为 $0.0067 、 0.0049$; 而未利用地转出因子最不活跃, 其中未利用地 $\rightarrow$ 林地、未利用地 $\rightarrow$ 草地、未利用地 $\rightarrow$ 城乡建设用地 3 个土地利用转移几率比因子均小 于 0.0001 。按转出土地利用类型分类,耕地 $\rightarrow$ 城乡 建设用地、林地 $\rightarrow$ 耕地、草地 $\rightarrow$ 林地、水域 $\rightarrow$ 耕地、 城乡建设用地 $\rightarrow$ 耕地、未利用地 $\rightarrow$ 水域等土地利用 转移几率比因子在各自转出土地类型因子中最为 活跃。

\section{4 结果与分析}

\section{1 模型结果可靠性检验}

生态系统服务价值预测值计算的准确性在于 回归结果的可靠性。因此,必须检验各变量的回归 系数是否符合理论预期, 以便作出可靠性检验的判 断(表3)。

从拟合程度来看, 调整后的 $R^{2}$ 为 $99.25 \%$, 可以 说明模型拟合情况比较好, 即土地利用转移几率比 因子对生态系统服务价值具有较高的解释能力。

(1) 虽然单位面积生态系统服务价值的使用可以使乡镇之间的生态系统服务价值具有可比性,提高模型的拟合效果,但可能导致所有年 份生态补偿与生态受偿的总金额不相等。 
表 2 各变量描述性统计

Table 2 Descriptive statistics of variables

\begin{tabular}{|c|c|c|c|c|c|}
\hline 变量 & 平均值 & 标准差 & 变量 & 平均值 & 标准差 \\
\hline 生态系统服务价值/(元/hm²) & 36209.8400 & 12162.3400 & 生态系统服务价值预测值/(元/hm²) & 36209.8400 & 11888.3600 \\
\hline 耕地 $\rightarrow$ 林地 & 0.0020 & 0.0076 & 水域 $\rightarrow$ 耕地 & 0.0013 & 0.0044 \\
\hline 耕地 $\rightarrow$ 草地 & 0.0001 & 0.0011 & 水域 $\rightarrow$ 林地 & 0.0002 & 0.0014 \\
\hline 耕地 一水域 & 0.0049 & 0.0187 & 水域 $\rightarrow$ 草地 & 0.0001 & 0.0009 \\
\hline 耕地 $\rightarrow$ 城乡建设用地 & 0.0067 & 0.0188 & 水域 $\rightarrow$ 城乡建设用地 & 0.0006 & 0.0072 \\
\hline 耕地 $\longrightarrow$ 未利用地 & 0.0001 & 0.0046 & 水域 $\rightarrow$ 未利用地 & 0.0004 & 0.0053 \\
\hline 林地 $\rightarrow$ 耕地 & 0.0015 & 0.0049 & 城乡建设用地 $\rightarrow$ 耕地 & 0.0005 & 0.0017 \\
\hline 林地 $\rightarrow$ 草地 & 0.0003 & 0.0024 & 城乡建设用地 $\rightarrow$ 林地 & 0.0001 & 0.0005 \\
\hline 林地 一水域 & 0.0005 & 0.0027 & 城乡建设用地 $\rightarrow$ 草地 & 0.0000 & 0.0003 \\
\hline 林地 $\rightarrow$ 城乡建设用地 & 0.0014 & 0.0064 & 城乡建设用地 一水域 & 0.0001 & 0.0017 \\
\hline 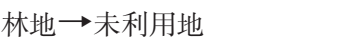 & 0.0000 & 0.0001 & 城乡建设用地 $\longrightarrow 未$ 未利用地 & 0.0000 & 0.0002 \\
\hline 草地 $\rightarrow$ 耕地 & 0.0001 & 0.0011 & 未利用地 $\rightarrow$ 耕地 & 0.0001 & 0.0011 \\
\hline 草地 $\rightarrow$ 林地 & 0.0004 & 0.0037 & 未利用地 $\rightarrow$ 林地 & 0.0000 & 0.0002 \\
\hline 草地 一水域 & 0.0001 & 0.0016 & 未利用地 $\rightarrow$ 草地 & 0.0000 & 0.0002 \\
\hline 草地 $\rightarrow$ 城乡建设用地 & 0.0001 & 0.0015 & 未利用地 $\rightarrow$ 水域 & 0.0004 & 0.0051 \\
\hline 草地一未利用地 & 0.0000 & 0.0002 & 未利用地 $\rightarrow$ 城乡建设用地 & 0.0000 & 0.0003 \\
\hline
\end{tabular}

注: “ $\rightarrow ”$ 表示土地利用转移方向符号。

\section{表 3 模型结果可靠性检验}

Table 3 Reliability verification of the modeling results

\begin{tabular}{|c|c|c|c|c|c|c|}
\hline 因变量 (mesv) & 耕地 & 林地 & 草地 & 水域 & 城乡建设用地 & 未利用地 \\
\hline \multirow[t]{2}{*}{ 耕地 } & & $36311.59 * * *$ & $8611.71 * * *$ & $53557.49 * * *$ & $-15046.09 * * *$ & $-9976.263 * * *$ \\
\hline & & $(820.44)$ & (2962.85) & (2165.607) & $(414.65)$ & (168.49) \\
\hline \multirow[t]{2}{*}{ 林地 } & $-35915.70 * * *$ & & $-30989.27^{* * *}$ & $28432.11^{* * *}$ & $-52957.22 * * *$ & -25369.63 \\
\hline & $(678.41)$ & & $(437.01)$ & (1591.90) & $(626.46)$ & $(24947.57)$ \\
\hline \multirow[t]{2}{*}{ 草地 } & $-5178.58 * * *$ & $29132.29 * * *$ & & $53889.42 * * *$ & $-18243.26^{* * *}$ & 14013.88 \\
\hline & (1115.16) & (911.26) & & (1698.02) & $(2567.06)$ & (33226.39) \\
\hline \multirow[t]{2}{*}{ 水域 } & $-62367.20 * * *$ & $-23438.73 * * *$ & $-55290.88^{* * *}$ & & $-61248.94 * * *$ & $-67807.95 * * *$ \\
\hline & $(956.25)$ & (1095.85) & (3781.89) & & $(2660.60)$ & (2285.99) \\
\hline \multirow[t]{2}{*}{ 城乡建设用地 } & $17861.14 * * *$ & $61123.03 * * *$ & $20135.36^{* * *}$ & $75833.52 * * *$ & & 4785.21 \\
\hline & $(2765.41)$ & $(5514.32)$ & $(3532.27)$ & $(1290.80)$ & & (7973.45) \\
\hline \multirow[t]{2}{*}{ 未利用地 } & $13326.36^{* * *}$ & $51208.36^{* * *}$ & $21591.72 * * *$ & $66087.02 * * *$ & -12238.34 & \\
\hline & (1453.19) & $(4978.31)$ & $(4656.96)$ & $(3067.86)$ & (10555.73) & \\
\hline
\end{tabular}

注: 常数项为 $888.89^{* * *}$,标准误为 $219.1628 ;$ mesv $_{t-1}$ 的估计系数为 $0.98^{* * * *}$,标准误为 0.0058 ; 调整后 $R^{2}$ 为 0.9925 。括号里的数值为标准误; ***表示在 $1 \%$ 的显著性水平下显著, **表示在 $5 \%$ 的显著性水平下显著。

从模型结果来看,各土地利用转移几率比因子的估 计系数比较符合理论预期。在显著的土地利用转 移几率比因子中, 由高生态价值系数用地转向低生 态价值系数用地的几率比因子均对生态系统服务 价值产生负向影响 (耕地 $\rightarrow$ 城乡建设用地、耕地 $\rightarrow$ 未利用地、林地 $\rightarrow$ 耕地、林地 $\rightarrow$ 草地、林地 $\rightarrow$ 城乡建
设用地、草地 $\rightarrow$ 耕地、草地 $\rightarrow$ 城乡建设用地、水域 $\rightarrow$ 耕地、水域 $\rightarrow$ 林地、水域 $\rightarrow$ 草地、水域 $\rightarrow$ 城乡建设用 地、水域 $\rightarrow$ 未利用地); 而由低生态价值系数用地转 向高生态价值系数用地的几率比因子均对生态系 统服务价值产生正向影响 (耕地 $\rightarrow$ 林地、耕地 $\rightarrow$ 草 地、耕地 $\rightarrow$ 水域、林地 $\rightarrow$ 水域、草地 $\rightarrow$ 林地、草地 $\rightarrow$ 
水域、城乡建设用地 $\rightarrow$ 耕地、城乡建设用地 $\rightarrow$ 林地、 城乡建设用地 $\rightarrow$ 草地、城乡建设用地 $\rightarrow$ 水域、未利 用地 $\rightarrow$ 耕地、未利用地 $\rightarrow$ 林地、未利用地 $\rightarrow$ 草地、未 利用地 $\rightarrow$ 水域）。因此,说明该模型可以很好地识 别生态系统服务价值的影响因子并且符合理论预 期,在一定程度上可以保证预测结果的可靠性。

\section{2 湖北省生态补偿的时空变化特征}

通过模型 (10)计算出湖北省各乡镇生态系统 服务价值的预测值, 并利用公式(11)计算各乡镇的 生态补偿金额。在 Stata 中按照生态补偿金额是否 大于 0 对生态补偿区与生态受偿区进行分组, 然后 利用 $K$ 均值的方法分别对 2000-2015 年生态补偿 区与生态受偿区的生态补偿(受偿)金额进行聚类, 最后根据聚类结果在 ArcGIS 中进行分类显示 (图 2)。

\subsection{1 湖北省生态补偿的时间变化}

从时间上来看, 湖北省发生生态补偿的乡镇单 元数量波动上升, 并且生态补偿总额保持增加的趋
势 (图 2)。从 2000-2015 年, 湖北省发生生态补偿 的乡镇单元由 2000 年的 486 个增长到 2015 年的 540 个, 增加了 54 个, 增长率为 $11.11 \%$; 其中低度、中度 和高度生态补偿的乡镇单元数量分别增长 $1.98 \%$ 、 $15.74 \% 、 50.00 \%$ 。其次,生态补偿总金额呈现逐年 增加的趋势, 2015 年生态补偿的总金额达到 17.25 亿元, 相比 2000 年的 14.38 亿元, 增加了 2.83 亿元, 增长率为 $19.96 \%$ 。另外,乡镇单元平均补偿金额也 呈现逐年递增的趋势, 2015 年发生生态补偿的乡镇 单元平均需要支付的生态补偿金额为 319.44 万元, 相比 2000 年 295.88 万元的平均生态补偿支付金额 高出 $7.96 \%$ 。2015 年湖北省 GDP 达到 29500.19 亿 元, 相比 2000 年增长了 $589.85 \%$; 湖北省经济社会 的发展对生态环境的索取程度以及范围不断扩大, 导致生态补偿金额和发生生态补偿的乡镇数量不 断增加

湖北省发生生态受偿的乡镇单元数量总体保 持减少的趋势, 而生态受偿总额呈现波动降低趋势

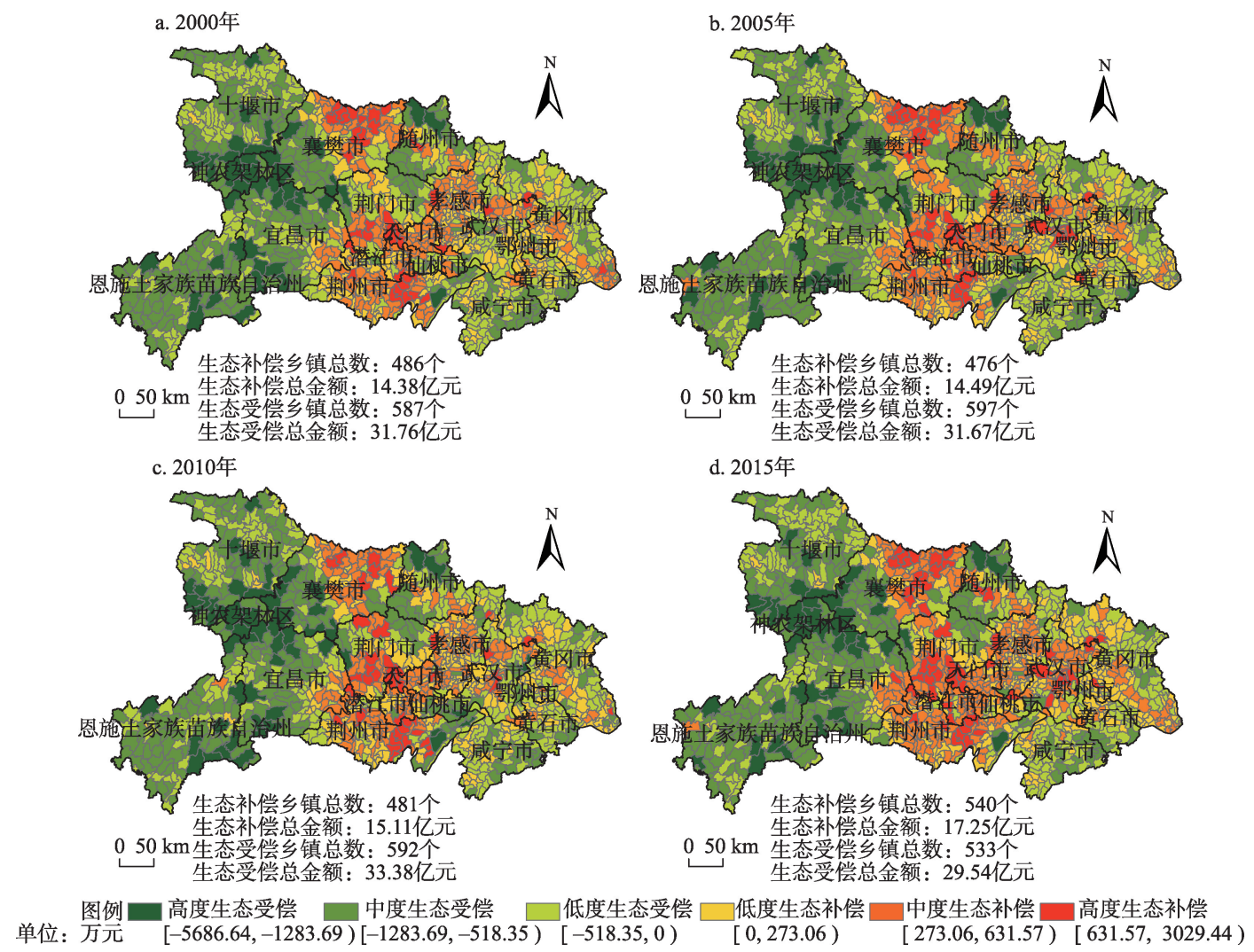

图 $22000-2015$ 年湖北省乡镇单元生态补偿金额及其时空变化

Figure 2 Payment for ecosystem services of townships and its spatial and temporal changes in Hubei Province, 2000-2015 
在原有的发生生态补偿的乡镇周边不断曼延,其中

（图 2）。2000-2015 年间,湖北省发生生态受偿的 乡镇单元由 2000 年的 587 个减少到 2015 年的 533 个, 减少了 $9.20 \%$; 其中, 高度、中度与低度生态受偿 的乡镇单元数量的变化率分别为 $2.38 \% 、-3.94 \%$ 、 $13.74 \%$ 。2000-2015 年间乡镇单元平均受偿金额 基本在 530 万 565 万元之间; 2015 年湖北省生态受 偿总金额达到 29.54 亿元, 相比 2000 年的 31.76 亿 元、2005年的 31.67 亿元、 2010 年的 33.38 亿元分别 减少了 $6.99 \% 、 6.73 \% 、 11.50 \%$ 。截至 2015 年底, 全 省城镇化率达到 $56.6 \%$, 相比 2000 年提高 $16.13 \%$, 湖北省城镇化的持续推进占用了大量的生态空间， 导致生态受偿金额与发生生态受偿的乡镇数量不 断减少。

\subsection{2 湖北省生态补偿的空间变化}

从空间上来看, 湖北省生态补偿与受偿的乡镇 单元空间格局基本保持不变, 局部略有变动 (图 2)。总体上看, 湖北省乡镇生态补偿呈现东高西低 的格局, 主要分布在以武汉城市圈为核心的江汉平 原以及汉江谷地, 包含襄阳市、荆门市、荆州市、潜 江市、天门市、孝感市、武汉市以及黄冈市的大部分 乡镇, 与湖北省重点开发区划定的区域基本一致 [24]。江汉平原与汉江中游是重要农业耕作区, 承担 着较多的农业生产功能, 而武汉城市圈承载了较多 的非农生产功能和高强度的人类活动 ${ }^{[32]}$ 。其中, 2000-2015 年间黄冈市的铁门岗乡, 荆门市的罗店 镇、曾集镇、沈集镇、五里铺镇、旧口镇, 荆州市的程 集镇、红城乡、黄歇口镇、汪桥镇、新沟镇、川店镇, 天门市的多宝镇、拖市镇、张港镇, 武汉市的祁家湾 街道, 襄栎市的七方镇、黄集镇、龙王镇、石桥镇等 乡镇 (街道)一直处于高度生态补偿区。表明这些 区域的生态系统服务价值对自然因素以及社会经 济因素的变化不敏感, 成为人类生产生活相对密集 和稳定的区域, 可以进行工厂、商业、住宅等建设活 动以及密集型的农业生产活动, 以避免人类活动范 围扩大对生态空间的占用。从局部地区来看, 武汉 市的发生生态补偿的乡镇数量增加较为明显。 2000 年武汉市发生生态补偿的乡镇有 34 个, 占全市 乡镇总数的 $55.74 \%$, 并且围绕武汉市中心分布。 2015 年武汉市发生生态补偿的乡镇比例为 $75.41 \%$,
2015 年发生高度生态补偿的乡镇单元数量比 2000 年增加了 4 个,增长了 $200 \%$ 。武汉市作为武汉城市 圈的核心城市, 其城市经济辐射范围随着时间不断 扩大, 农田和生态用地持续转变为城乡建设用地。 通过对武汉市土地利用分类数据统计可知, 2015 年 武汉市城乡建设用地面积相比 2000 年增长了 $93.39 \%$ 。

湖北省生态受偿的乡镇主要分布在湖北省东 部与西部地区, 与湖北省山脉分布格局十分契合, 包含鄂西南武陵山区、鄂西北秦巴山区、鄂东南幕 阜山区和鄂东北大别山区等区域,基本包含了重点 生态功能区划定的区域 ${ }^{[2]}$ 。其中, 2000-2015 年恩 施自治州的沿渡河镇、野三关镇、容美镇、柏杨坝 镇、沙道沟镇、长潭河侗族乡, 荆门市的栗溪镇, 荆 州市的滨湖街道, 神农架林区的红坪镇、木鱼镇、宋 洛乡,十堰市的大木厂镇、门古寺镇、桥上乡、柳林 乡、丰溪镇, 随州市的万和镇、殷店镇, 襄紮市的马 桥镇、歇马镇、紫金镇、李庙镇, 宜昌市的五峰镇、古 夫镇、水月寺镇、榛子乡、雾渡河镇、樟村坪镇、茅坪 场镇等乡镇 (街道)一直保持在高度生态受偿区。 这些区域是生态系统服务重要且稳定的提供者,应 该建立生态服务重点功能区, 严格限制土地用途转 变以免造成生态系统的破坏与生态服务功能的弱 化。从局部地区来看,在江汉平原湖泊湿地保护区 内的生态受偿乡镇逐渐减少, 可能是武汉城市圈的 扩张导致这些乡镇逐步向生态补偿区过渡。这些 区域可以适当地建立缓冲区, 避免城镇向其他重要 的生态功能区扩张; 可以实施点状开发, 借助湿地 景观发展旅游观光产业, 实现区域绿色协调发展。

\section{5 结论与讨论}

\section{1 结论}

本文以环境正义理论为基础, 通过经济数学的 方法推导出区域生态补偿标准的理论模型以解决 小尺度下社会经济统计参数缺失的问题。主要研 究结论如下:

(1) 从湖北省乡镇单元的生态补偿金额以及分 区结果来看, 本文设计的小尺度生态补偿理论模型 可以很好地解决小尺度下社会经济数据缺失无法 
进行生态补偿标准测算的问题,并且该模型划定的 湖北省生态补偿区与生态受偿区分别包含了大部 分重点开发区、重点生态功能区划定的区域, 验证 了小尺度下区域生态补偿理论模型设计的可靠性。

(2) 湖北省整体生态环境水平存在恶化的可 能, 总体上其生态补偿金额呈现增加的趋势, 而生 态受偿金额呈现减少的趋势。从生态补偿来看, 2015 年湖北省乡镇生态补偿总额为 17.25 亿元, 相 比 2000 年增长了 $19.96 \%$; 发生生态补偿的乡镇主 要分布在江汉平原以及汉江谷地。从生态受偿来 看, 湖北省生态受偿总金额为 29.54 亿元, 相比 2000 年减少了 $6.99 \%$; 发生生态受偿的乡镇主要分布在 鄂西南武陵山区、鄂西北秦巴山区、鄂东南幕阜山 区和鄂东北大别山区等区域, 与湖北省山脉分布格 局十分契合。

\section{2 讨论}

虽然该模型可以有效地规避社会经济统计参 数的缺失问题, 解决小尺度下生态补偿缺失的问 题,但是依然需要关注理论和技术上的两个问题:

第一,该模型计算的单个年份的生态补偿与生 态受偿金额不满足 “谁受益、谁付费” 的原则。从理 论上来讲, 只要保证样本单元面积相等, 一定可以 使纳人到回归模型中所有年份的生态补偿与生态 受偿总金额相等,在总量上可以满足“谁受益、谁付 费” 的原则, 但是无法保证单个年份的生态补偿与 生态受偿金额相等。

第二, 该模型以回归方程作为主要工具, 对于 样本量和数据期数具有一定的要求。从技术上来 看, 回归模型一般需要大样本、多时期的面板数据 才能保证得到比较可靠的结果, 以消除界面数据可 能导致伪回归的问题 ${ }^{[19,22]}$ 。在遇到小样本时, 建议 使用网格对研究区域等面积细分并以此作为样本 单元, 然后利用本文设计的理论模型与方法测算每 个网格内的生态补偿金额,最后利用行政区矢量图 对网格内的生态补偿金额求和即可得到行政区内 的生态补偿总额。因此, 在保证样本量足够的前提 下, 本文设计的小尺度区域生态补偿标准理论模型 不仅可以计算县级以上行政单元的生态补偿金额， 也可以在指定的区域进行区域生态补偿的计算。

\section{参考文献(References):}

[1] 李国平, 王奕淇, 张文彬. 区域分工视角下的生态补偿研究[J]. 华东经济管理, 2016, 30(1): 12-18. [Li G P, Wang Y Q, Zhang W B. A study of ecological compensation from the perspective of regional division[J]. East China Economic Management, 2016, 30 (1): 12-18.]

[2] 丁振民, 姚顺波. 区域生态补偿均衡定价机制及其理论框架研 究[J]. 中国人口·资源与环境, 2019, 29(9): 99-108. [Ding Z M, Yao S B. Research on the equilibrium pricing mechanism and theoretical framework of regional ecological compensation[J]. China Population, Resources and Environment, 2019, 29(9): 99-108.]

[3] 文兰娇, 张晶晶. 国土空间管制、土地非均衡发展与外部性研 究: 回顾与展望[J]. 中国土地科学, 2015, 29(7): 4-12. [Wen L J, Zhang J J. Progress and trends of land spatial regulation, unbalanced development and spatial externalities[J]. China Land Sciences, 2015, 29(7): 4-12.]

[4] 金贵, 邓祥征, 张倩, 等. 武汉城市圈国土空间综合功能分区[J]. 地理研究, 2017, 36(3): 514-552. [Jin G, Deng X Z, Zhang Q, et al. Comprehensive function zoning of national land space for $\mathrm{Wu}$ han metropolitan region[J]. Geographical Research, 2017, 36(3): 514-552.]

[5] 国务院办公厅. 关于健全生态保护补偿机制的意见[EB/OL]. (2016-05-13) [2019-02-20]. http://www.gov.cn/zhengce/content/ 2016-05/13/content_5073049.htm. [General Office of the State Council. Opinions on Perfecting the Compensation Mechanism of Ecological Protection[EB/OL]. (2016-05-13) [2019-02-20]. http: //www.gov.cn/zhengce/content/2016-05/13/content_5073049.htm.]

[6] 中共中央国务院. 关于建立更加有效的区域协调发展新机制的 意见[EB/OL]. (2018-11-18) [2019-02-20]. http://www.gov.cn/ zhengce/2018-11/29/content_5344537.htm. [Central Committee of the Communist Party of China and the State Council of the People's Republic of China. Views on the Establishment of a New Mechanism for More Effective Regional Coordinated Development[EB/OL]. (2018-11-18) [2019- 02-20]. http://www.gov.cn/ zhengce/2018-11/29/content_5344537.htm.]

[7] 李国平, 李㴋. 国家重点生态功能区的生态补偿标准、支付额度 与调整目标 $[J]$. 西安交通大学学报(社会科学版), 2017, 37(2): 1-9. [Li G P, Li X. Ecological compensation standard, payment amount and adjustment target in national key ecological function areas[J]. Journal of Xi' an Jiaotong University (Social Sciences), 2017, 37(2): 1-9.]

[ 8 ] Engel S, Pagiola S, Wunder S. Designing payments for environmental services in theory and practice: An overview of the issues[J]. Ecological Economics, 2008, 65(4): 663-674.

[9] Carpenter S R, Mooney H A, Agard J, et al. Science for managing ecosystem services: Beyond the millennium ecosystem assessmen [J]. Proceedings of the National Academy of Sciences of the Unit- 
ed States of America, 2009, 106(5): 1305-1312.

[10] 张成福, 聂国良. 环境正义与可持续性公共治理[J]. 行政论坛, 2019, 26(1): 93-100. [Zhang C F, Nie G L. Environmental justice and sustainable public governance[J]. Administrative Tribune, 2019, 26(1): 93-100.]

[11] 王泽琳, 张如良, 吴欢. 跨流域调水的公正问题: 基于环境正义 的分析视角 [J]. 中国环境管理, 2019, 11(2): 101-105. [Wang Z $\mathrm{L}$, Zhang R L, Wu H. The justice of inter-basin water transfer based on environmental justice perspective[J]. Chinese Journal of Environmental Management, 2019, 11(2): 101-105.]

[12] Ferraro P J. Asymmetric information and contract design for payments for environmental services[J]. Ecological Economics, 2008, 65(4): 810-821.

[13] 刘春腊, 刘卫东, 陆大道, 等. 2004-2011 年中国省域生态补偿 差异分析[J]. 地理学报, 2015, 70(12): 1897-1910. [Liu C L, Liu W D, Lu D D, et al. China's provincial eco-compensation difference in 2004-2011[J]. Acta Geographica Sinica, 2015, 70(12): 1897-1910.]

[14] 潘竟虎. 甘肃省区域生态补偿标准测度[J]. 生态学杂志, 2014, 33(12): 3286-3294. [Pan J H. Regional eco-compensation standard in Gansu Province[J]. Chinese Journal of Ecology, 2014, 33 (12): 3286-3294.]

[15] 陈源泉, 高旺盛. 基于生态经济学理论与方法的生态补偿量化 研究[J]. 系统工程理论与实践, 2007, 27(4): 165-170. [Chen Y Q, Gao W S. How to determine the payment amount of ecological compensation: Based on the theories and methods of ecological economics[J]. System Engineering Theory and Practice, 2007, 27 (4): 165-170.]

[16] 杨璐迪, 曾晨, 焦利民, 等. 基于生态足迹的武汉城市圈生态承 载力评价和生态补偿研究[J]. 长江流域资源与环境, 2017, 26 (9): 1332-1341. [Yang L D, Zeng C, Jiao L M, et al. Evaluation on ecological carrying capacity and ecological compensation of $\mathrm{Wu}-$ han urban agglomeration based on ecological footprint[J]. Resources and Environment in Yangtze Basin, 2017, 26(9): 1332-1341.]

[17] 马恩朴, 蔡建明, 林静, 等. 远程耦合视角下的土地利用/覆被变 化解释[J]. 地理学报, 2019, 74(3): 421-431. [Ma E P, Cai J M, Lin J, et al. Explanation of land use/cover change from the perspective of tele-coupling[J]. Acta Geographica Sinica, 2019, 74 (3): 421-431.]

[18] Beh E, Tran D, Hudson I. A reformulation of the aggregate association index using the odds ratio[J]. Computational Statistics \& Data Analysis, 2013, 68: 52-65.

[19] 陈强. 高级计量经济学及 Stata 运用(第二版)[M]. 北京: 高等教 育出版社, 2014. [Chen Q. Advanced Econometrics and Stata Application (2nd Edition) [M]. Beijing: Higher Education Press, 2014.]

[20] Lambin E F, Turner B L, Geist H J, et al. The causes of land-use and land-cover change: Moving beyond the myths[J]. Global Envi- ronmental Change, 2001, 11(4): 261-269.

[21] Reid W V, Mooney H A, Cropper A, et al. Millennium Ecosystem Assessment: Ecosystems and Human Well-being: Synthesis[M]. Washington DC: Island Press, 2005.

[22] 丁振民, 姚顺波. 陕西省耕地转移对生态系统服务价值的影响 [J]. 资源科学, 2019, 41(6): 1070-1081. [Ding Z M, Yao S B. Effects of cultivated land transition on ecosystem service value in Shaanxi Province of China[J]. Resources Science, 2019, 41(6): 1070-1081.]

[23] Farley J, Costanza R. Payments for ecosystem services: From local to global[J]. Ecological Economics, 2010, 69(11): 2060-2068.

[24] 孙璇, 曾菊新, 陈四云, 等. 顾及生态损益的生态补偿支付次序 研究: 以湖北省为例[J]. 经济地理, 2018, 38(5): 170-178. [Sun X, Zeng J X, Chen S Y, et al. Ecological compensation payment order with considering the ecological profit and loss: The case of Hubei Province[J]. Economic Geography, 2018, 38(5): 170-178.]

[25] 湖北省人民政府. 关于建立健全生态保护补偿机制的实施意见 [EB/OL]. (2018-02-12) [2019-06-30]. http://www.hubei.gov.cn/ govfile/ezbf/201803/t20180306_1259441.shtml. [People's Government of Hubei Province. Implementation Opinions on Establishing and Improving the Compensation Mechanism for Ecological Protection[EB/OL]. (2018-02-12) [2019-06-30]. http://www. hubei.gov.cn/govfile/ezbf/201803/t20180306_1259441.shtml.]

[26] Daily G C. Nature's Services: Societal Dependence on Natural Ecosystems[M]. Washington: Island Press, 1997.

[27] Costanza R, d' Arge R, de Groot R, et al. The value of the world's ecosystem services and natural capital[J]. Nature, 1997, 387: 253260.

[28] 谢高地, 甄霖, 鲁春霞, 等. 一个基于专家知识的生态系统服务 价值化方法 [J]. 自然资源学报, 2008, 23(5): 911-919. [Xie G D, Zhen L, Lu C X, et al. Expert knowledge-based valuation method of ecosystem services in China[J]. Journal of Natural Resources, 2008, 23(5): 911-919.]

[29] 熊鹰, 张方明, 龚长安, 等. LUCC 影响下湖南省生态系统服务 价值时空演变[J]. 长江流域资源与环境, 2018, 27(6): 13971408. [Xiong Y, Zhang F M, Gong C A, et al. Spatial-temporal evolvement of ecosystem service value in Hunan Province based on LUCC[J]. Resources and Environment in Yangtze Basin, 2018, 27(6): 1397-1408.]

[30] 刘纪远, 匡文慧, 张增祥, 等. 20 世纪 80 年代末以来中国土地利 用变化的基本特征与空间格局[J]. 地理学报, 2014, 69(1): 314. [Liu J Y, Kuang W H, Zhang Z X, et al. Spatiotemporal characteristics, patterns and causes of land use changes in China since the late 1980s[J]. Acta Geographica Sinica, 2014, 69(1): 3-14.]

[31] 中国知网. 全国农产品成本收益汇编[EB/OL]. (2015-07-30) [2019-06-30]. http://cyfd.cnki.com.cn/N2015100281.htm. [CNKI. A Compilation of Costs and Benefits of Agricultural Products in China[EB/OL]. (2015-07-30) [2019-06-30]. http://cyfd.cnki.com.cn/ 
N2015100281.htm.]

[32] 崔家兴, 顾江, 孙建伟, 等. 湖北省三生空间格局演化特征分析

[J]. 中国土地科学, 2018, 32(8): 67-73. [Cui J X, Gu J, Sun J W, et al. The spatial pattern and evolution characteristics of the production, living and ecological space in Hubei Province[J]. China Land Science, 2018, 32(8): 67-73.]

\title{
Model and measurement of payment for ecosystem services at small scale
}

\author{
DING Zhenmin ${ }^{1,2}$, YAO Shunbo ${ }^{1,2}$ \\ (1. Center for Resource Economics and Environmental Management, Northwest A\& F University, Yangling 712100, China; \\ 2. College of Economic Management, Northwest A\& F University, Yangling 712100, China)
}

\begin{abstract}
Based on the theory of environmental justice, this study examined the relationship between the odds ratio of land use transition and ecosystem service value to solve the problem of lack of socioeconomic statistics at a small scale. The results show that: (1) the theoretical model of payment for ecosystem services designed in this study can effectively solve the problem of lack of socioeconomic statistics at a small scale and determine the paying areas and receiving areas of payment for ecosystem services which are consistent with most parts of the key development areas and key ecological function areas in Hubei Province respectively. It verifies the reliability of model designed in this paper. (2) Ecological environment level is descending on the whole in the Hubei Province. The number of towns and total amount of payment for ecosystem services in Hubei Province showed an overall upward trend, while receiving towns' are reverse. The total amount of payment for ecosystem services and reception of ecological compensation are RMB 1.725 billion yuan and 2.954 billion yuan, respectively, in Hubei Province in 2015. In addition, the spatial pattern of paying areas and receiving areas of payment for ecosystem services basically remains unchanged, but there are a little of changes in local areas. The theoretical model of payment for ecosystem services designed in this paper can provide a solution to the spatial ecological imbalance at small scale.
\end{abstract}

Key words: payment for ecosystem services; environmental justice; ecosystem service value; theoretical model; small scale; Hubei Province 